Article

\title{
Effects of a Non-Thermal Atmospheric Pressure Plasma Jet with Different Gas Sources and Modes of Treatment on the Fate of Human Mesenchymal Stem Cells
}

\author{
Tae-Yun Kang ${ }^{1,2}$, Jae-Sung Kwon ${ }^{1,2, *} \oplus$, Naresh $\operatorname{Kumar}^{3}{ }^{\circledR}$, Eun Ha Choi ${ }^{4} \oplus$ and \\ Kwang-Mahn Kim ${ }^{1,2}$ (D) \\ 1 Department and Research Institute of Dental Biomaterials and Bioengineering, Yonsei University College of \\ Dentistry, Seoul 03722, Korea; tykang@yuhs.ac (T.-Y.K.); kmkim@yuhs.ac (K.-M.K.) \\ 2 BK21 PLUS Project, Yonsei University College of Dentistry, Seoul 03722, Korea \\ 3 Research Group PLASMANT, Department of Chemistry, University of Antwerp, \\ 2610 Wilrijk-Antwerp, Belgium; Naresh.Kumar@uantwerpen.be \\ 4 Plasma Bioscience Research Center, Kwangwoon University, Seoul 01897, Korea; ehchoi@kw.ac.kr \\ * Correspondence: jkwon@yuhs.ac; Tel.: +82-2-2228-3081
}

Received: 29 July 2019; Accepted: 6 November 2019; Published: 11 November 2019

check for updates

\begin{abstract}
Despite numerous attempts to use human mesenchymal stem cells (hMSCs) in the field of tissue engineering, the control of their differentiation remains challenging. Here, we investigated possible applications of a non-thermal atmospheric pressure plasma jet (NTAPPJ) to control the differentiation of hMSCs. An air- or nitrogen-based NTAPPJ was applied to hMSCs in culture media, either directly or by media treatment in which the cells were plated after the medium was exposed to the NTAPPJ. The durations of exposure were 1, 2, and $4 \mathrm{~min}$, and the control was not exposed to the NTAPPJ. The initial attachment of the cells was assessed by a water-soluble tetrazolium assay, and the gene expression in the cells was assessed through reverse-transcription polymerase chain reaction and immunofluorescence staining. The results showed that the gene expression in the hMSCs was generally increased by the NTAPPJ exposure, but the enhancement was dependent on the conditions of the exposure, such as the source of the gas and the treatment method used. These results were attributed to the chemicals in the extracellular environment and the reactive oxygen species generated by the plasma. Hence, it was concluded that by applying the best conditions for the NTAPPJ exposure of hMSCs, the control of hMSC differentiation was possible, and therefore, exposure to an NTAPPJ is a promising method for tissue engineering.
\end{abstract}

Keywords: non-thermal atmospheric pressure plasma; mesenchymal stem cells; tissue engineering; regenerative medicine

\section{Introduction}

Tissue engineering and regenerative medicine is a field that involves replacing or regenerating human cells and tissues to restore or even improve the function of the human body [1]. Human mesenchymal stem cells (hMSCs) are derived from the bone marrow, and are often considered to be highly promising therapeutic agents in this field due to their self-renewal and multilineage differentiation capabilities [2]. The hMSCs are known to have the potential to differentiate into osteoblasts, chondrocytes, adipocytes, etc. [3-6], but the control of their differentiation still remains to be resolved, which will be the key to successful tissue engineering and regenerative medicine in the future. 
The use of a non-thermal atmospheric pressure plasma jet (NTAPPJ) has drawn a great deal of interest from researchers, especially because of its possible applications in biological fields such as the treatment of biomaterial surfaces $[7,8]$ and the direct treatment of both microorganisms $[9,10]$ and living cells and tissue [11-13]. Therefore, NTAPPJ has advantages in terms of the production of electrons, ions, and free radicals below body temperature, as it ensures no thermal damage is done to the target $[12,14]$.

Recent studies have indicated that a certain duration of exposure to plasma may have bioactive effects, such as improved cell attachment and proliferation [13-15]. A study that considered the use of adipose-tissue-derived stem cells (ASCs) indicated that there was an increase in the proliferation of cells by NTAPPJ exposure, which did not affect their stemness [16]. In another study in which the effect of NTAPPJ exposure was considered on human mesenchymal stem cells isolated from periodontal ligaments (hPDL-MSCs), it was evident that the hPDL-MSCs possessed all of the typical MSC properties, including the capacity for multilineage differentiation [17]. Finally, in a study in which human peripheral blood mesenchymal stem cells (hPB-MSCs) were exposed to an NTAPPJ, the effects were variable in accordance with their distance from the plasma plume, where both dead cells and viable cells were evident [18]. Despite these few papers describing the investigation of the effects of NTAPPJs on stem cells, studies have been limited in terms of investigating the proliferation and multilineage potential rather than considering the direction of differentiation. Additionally, no study has investigated the effects of NTAPPJs on the differentiation of human mesenchymal stem cells.

Hence, the aim of the study was to investigate the effects of an NTAPPJ on the differentiation of hMSCs for possible applications in the field of tissue engineering and regenerative medicine.

\section{Materials and Methods}

\subsection{Human Mesenchymal Stem Cells}

The hMSCs in this study were purchased commercially (Lonza, Allendale, NJ, USA) and cultured in Dulbecco's Modified Eagle's Medium (Gibco, Grand Island, NY, USA) without any differentiation supplements. The passages of the cells were maintained low, between three and five subcultures, to maintain their multilineage capabilities.

\subsection{Non-Thermal Atmospheric Pressure Plasma Jet}

The NTAPPJ used in this study was developed at the Plasma Bioscience Research Center of Kwangwoon University, Korea, and was used in our previous studies for different purposes $[7,8,13]$. The gas was supplied with either compressed air or nitrogen with a controlled rate of $0.5 \mathrm{~L} / \mathrm{min}$ using a mass flow controller (AFC600, Atrovac, Yongin, Korea). All hMSC exposures to the NTAPPJ were carried out while the hMSCs were suspended in culture media. In terms of the direct application of the NTAPPJ [13], $1 \mathrm{~mL}$ of culture medium with $1 \times 10^{4}$ cells was exposed to the NTAPPJ for 1,2 , and $4 \mathrm{~min}$, and the experiments were carried out in standard 12-well culture plates (SPL, Daegu, Korea), with the distance between the medium and the tip of the NTAPPJ flume at $3 \mathrm{~mm}$. The media-treated samples were also exposed to the NTAPPJ in a similar way, but in this study, the culture medium without cells was exposed to the NTAPPJ first, and then the cells were exposed to the NTAPPJ-treated medium [13]. The control samples were not exposed to the NTAPPJ.

\subsection{Cell Attachment}

The number of hMSCs attached on the culture well plate after $24 \mathrm{~h}$ of NTAPPJ exposure along with any unattached cells was assessed using a water-soluble tetrazolium salt (WST, Daeil Lab, Seoul, Korea) assay according to previously described methods $[13,19,20]$. As the optical density measured from the WST assay was directly proportional to the number of cells attached after the NTAPPJ exposure, the results are expressed as the percentage of the optical absorbance of the control. 
Additionally, the morphology of the attached cells was assessed using fluorescent dyes and a confocal laser microscope. After culturing for $4 \mathrm{~h}$ under the previously described conditions, the cells were stained with DAPI (nuclei are blue, Invitrogen, Grand Island, NY, USA) and rhodamine phalloidin (actin filaments are red, Invitrogen, Grand Island, NY, USA), and then the cells were visualized under a confocal laser microscope (LSM700, Carl-Zeiss, Thornwood, NY, USA).

\subsection{Cell Differentiation}

The differentiation of the hMSCs was assessed by the expression of the peroxisome proliferator-activated receptor gamma (PPARG), collagen type 2 (COL II), and osteopontin (OPN) genes, which are indicators of adipogenesis, chondrogenesis, and osteogenesis, respectively [3,21,22]. The primer sequences used in this study are listed in Table 1 . The cells were cultured for 14 days, and the total RNA was extracted from the cells using TRIzol reagent (Ambion, Austin, TX, USA). The RNA was then reverse transcribed into cDNA using an Omniscript RT kit (Qiagen, Hilden, Germany), which was then mixed with an appropriate primer and SYBR green assay (Applied Biosystems, Foster City, CA, USA) for analysis by real-time reverse transcription polymerase chain reaction (RT-PCR). GAPDH was used as the housekeeping gene, and the results are presented as the relative fold increase in gene expression over that of the control (the $2-\Delta \Delta C T$ method).

Additionally, the confirmation of OPN gene expression by real-time RT-PCR analysis was carried out using immunofluorescence staining of cells with an anti-osteopontin antibody (1:100, Santa Cruz Biotechnology, Dallas, TX, USA) where the goat anti-mouse IgG-FITC (1:100, Santa Cruz Biotechnology, Dallas, TX, USA) was used as the secondary antibody to stain the cells. The results were observed using a confocal laser microscope (LSM700, Carl-Zeiss, Oberkochen, Germany). The brightfield image was also obtained from the control group using the same microscope, to indicate the number of cells present in the field of view for each group.

Finally, alizarin red staining was performed to observe mineralized bone-like cells on day 7 . In brief, the cells on a plate with the scaffolds were washed with PBS and fixed with 70\% ethanol for $1 \mathrm{~h}$. The fixed cells were stained for $10 \mathrm{~min}$ with $40 \mathrm{mM}$ alizarin red staining solution, $\mathrm{pH} 4.2$, at $25^{\circ} \mathrm{C}$. After washing off the excess dye with deionized water, the bound stain was eluted with $10 \%$ cetylpyridinium chloride, and the absorbance of the solution was measured at $562 \mathrm{~nm}$. The measured absorption values were divided by the percentage values obtained from the number of cells attached in each group.

Table 1. Primer sequences of the genes used for reverse transcription polymerase chain reaction (RT-PCR).

\begin{tabular}{ccc}
\hline Genes & Forward Sequences & Backward Sequences \\
\hline PPARG & 5'-GCA GGA GCA GAG CAA AGA G-3' $^{\prime}$ & 5'-TGG TCG TTC AAG TCA AGA TTT AC-3' $^{\prime}$ \\
COL II & 5'-GGA GCA GCA AGA GCA AGG AGA AG-3' $^{\prime}$ 5'-TGG ACA GCA GGC GTA GGA AGG-3' \\
OPN & 5'-AGA CCA TGC AGA GAG CGA G-3' $^{\prime}$ & 5'-ACG TCT GCT TGT GTG CTG G-3' $^{\prime}$ \\
\hline
\end{tabular}

\subsection{Statistical Analysis}

The statistical analyses of the results for both the attached cells and the cells that had differentiated were carried out using a one-way ANOVA test with the IBM SPSS statistics 20 program (IBM, Armonk, NY, USA). Statistical significance was considered to be $p<0.05$.

\section{Results}

\subsection{Cell Attachment}

The results of the cell attachment assessment according to the WST assays are shown in Figure 1. The results revealed that there were no significant differences in the results between the control group and all of the test groups except that of the hMSCs exposed for $4 \mathrm{~min}$ to the air-flowing NTAPPJ by the direct method (Figure 1a). The findings indicated that, in general, neither the air- nor nitrogen-flowing NTAPPJs had an effect on the attachment of the hMSCs. 
(a)

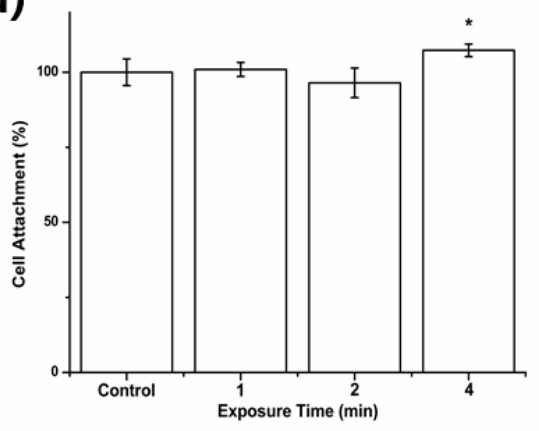

(c)

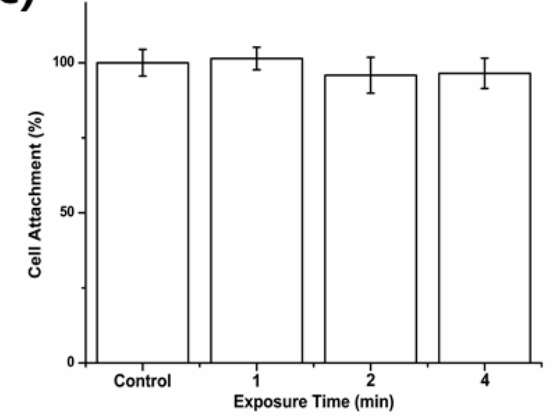

(b)

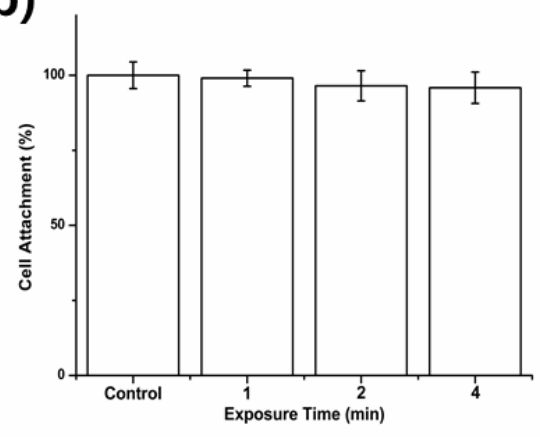

(d)

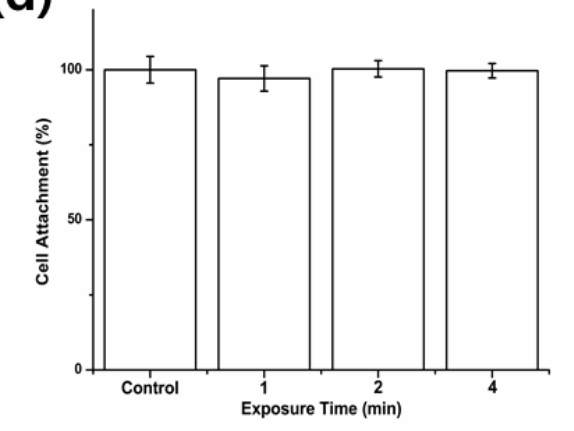

Figure 1. Human mesenchymal stem cells (hMSCs) attached after $24 \mathrm{~h}$ of cell culture following different durations of plasma exposure to (a) the air-flowing non-thermal atmospheric pressure plasma jet (NTAPPJ) by the direct method, (b) the air-flowing NTAPPJ by the media-treatment method, (c) the nitrogen-flowing NTAPPJ by the direct method, and (d) the nitrogen-flowing NTAPPJ by the media-treatment method (* significant at $p<0.05)$.

The morphology of the cells after $4 \mathrm{~h}$ of incubation was examined using immunofluorescent images, and the results are shown in Figure 2. A rounded cell morphology with relatively undeveloped actin filaments was evident for the control cells (Figure 2a), which appeared similar to the morphology of the cells in the test groups (Figure $2 b-e$ ).

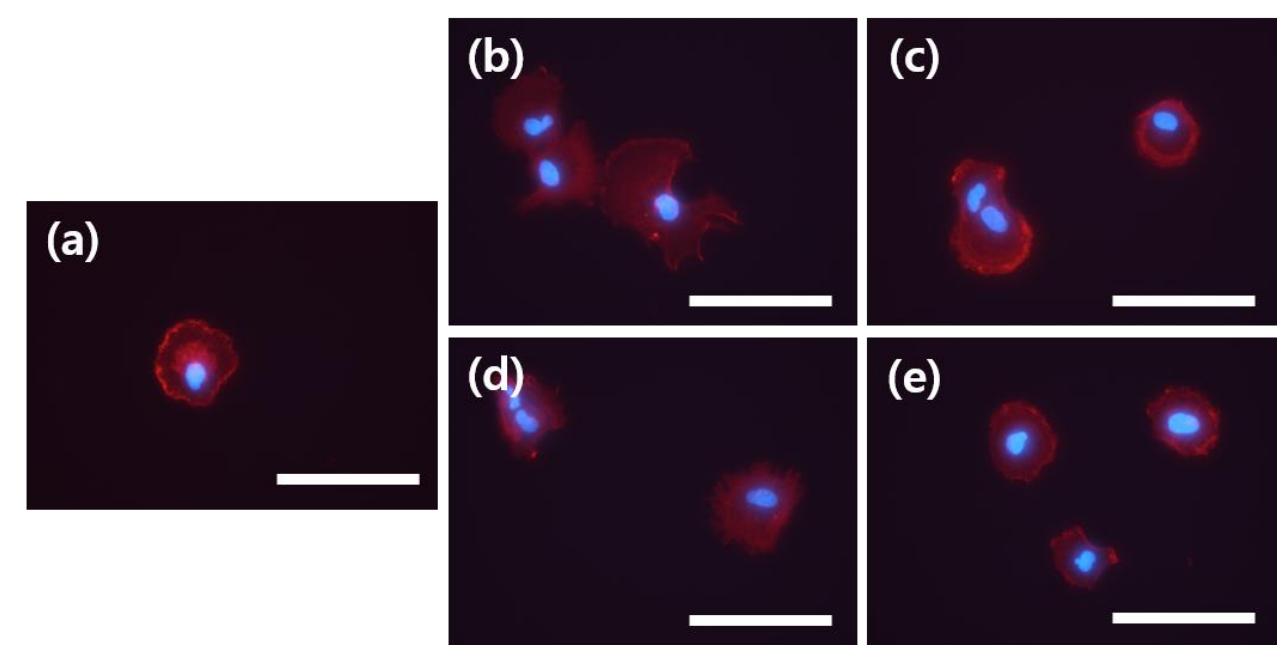

Figure 2. Human mesenchymal stem cell morphology after $4 \mathrm{~h}$ of cell culture following (a) no exposure to plasma (control), (b) direct exposure to the air-flowing NTAPPJ for $4 \mathrm{~min}$, (c) media treatment exposure to the air-flowing NTAPPJ for $4 \mathrm{~min}$, (d) direct exposure to the nitrogen-flowing NTAPPJ for $4 \mathrm{~min}$, and (e) media treatment exposure to the nitrogen-flowing NTAPPJ for $4 \mathrm{~min}$. Scale bar is $100 \mu \mathrm{m}$. 


\subsection{Cell Differentiation}

The results of the hMSC differentiation experiments following exposure to the NTAPPJs are shown in Figure 2. The expression of PPARG, COL II, and OPN indicated the adipogenesis, chondrogenesis, and osteogenesis, respectively.

Generally, for the expression of all genes tested in this study, the air-flowing NTAPPJ resulted in better differentiation than did the nitrogen-flowing NTAPPJ (Figure 3a-c).

(a)
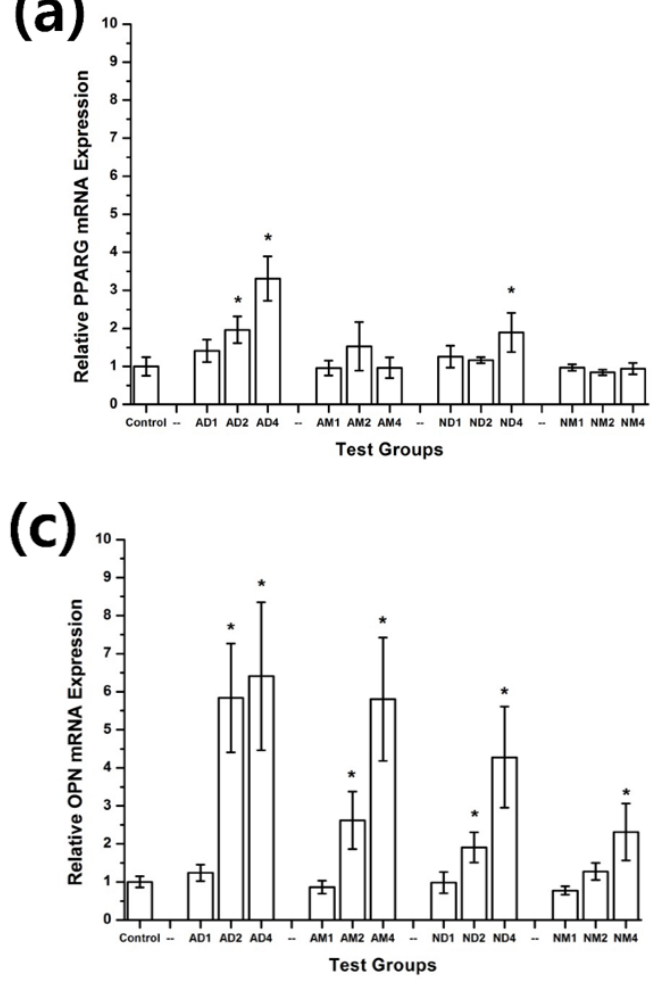

(b)

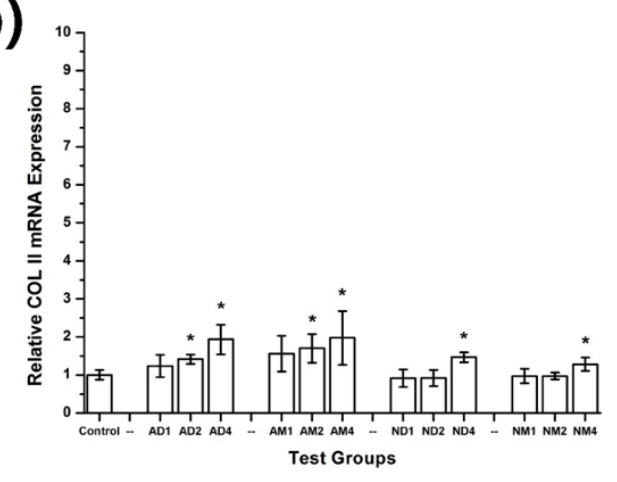

Figure 3. Relative gene expression in the human mesenchymal stem cells (hMSCs) after 14 days of cell culture following different durations of plasma exposure by the NTAPPJ: (a) PPARG, (b) COL II, and (c) OPN. The results are expressed as the relative fold increase compared to that of the control, with GAPDH as the housekeeping gene. Each test group was coded as follows: AD, exposed to the air-flowing NTAPPJ by the direct method; AM, exposed to the air-flowing NTAPPJ by the media-treatment method; ND, exposed to the nitrogen-flowing NTAPPJ by the direct method; and NM, exposed to the nitrogen-flowing NTAPPJ by the media-treatment method. The number after each code indicates the duration of the exposure to the NTAPPJ in minutes $\left({ }^{*}\right.$ significant at $\left.p<0.05\right)$.

In terms of adipogenesis, expression of PPARG was increased as the duration of exposure to the NTAPPJ increased through the direct method (Figure 3a). However, there was no significant effect when the NTAPPJ exposure was carried out using the media-treatment method (Figure 3a).

In terms of chondrogenesis and osteogenesis, the expression of COL II and OPN following exposure to the NTAPPJ, either by the direct or media-treatment method, showed significantly higher levels compared to those of the control for the longer duration of exposure (Figure 3b,c).

The results were confirmed using the fluorescent staining of OPN, as it showed the most dramatic increase of gene expression in RT-PCR analysis following the NTAPPJ exposure, compared to PPARG or COL II. The results were in concordance with RT-PCR analysis, as brightly colored green staining was evident for hMSCs directly exposed to 4 min of the air-flowing NTAPPJ by the direct and media-treatment methods (Figure $4 \mathrm{~b}, \mathrm{c}$ ) and hMSCs exposed to $4 \mathrm{~min}$ of the nitrogen-flowing NTAPPJ by the direct method (Figure 4d), when compared to the numbers of cells present in the culture (Figure 4f). There was no evidence of any fluorescence for the control samples (Figure 4a), and hMSCs 
exposed to $4 \mathrm{~min}$ of the nitrogen-flowing NTAPPJ by the media-treatment method showed a brighter color than control samples but a weaker signal than other test samples (Figure 4e).
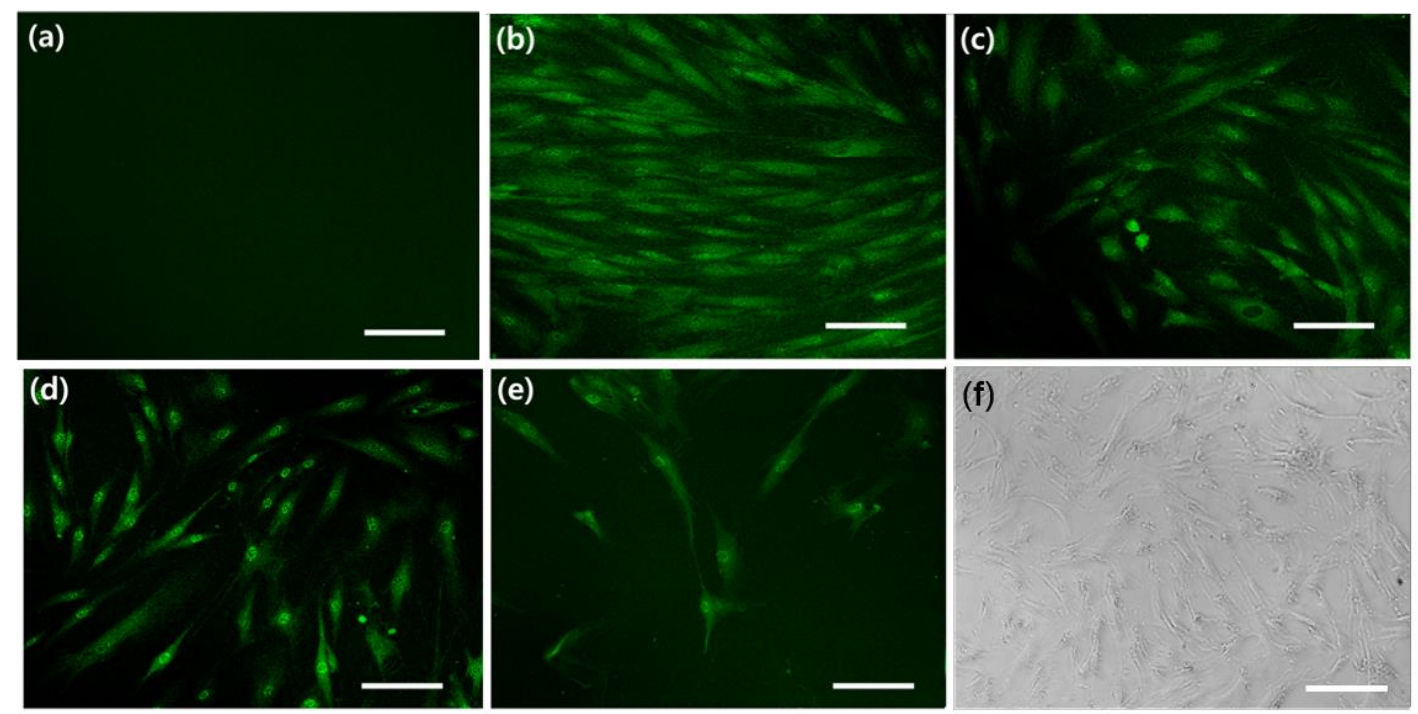

(f)

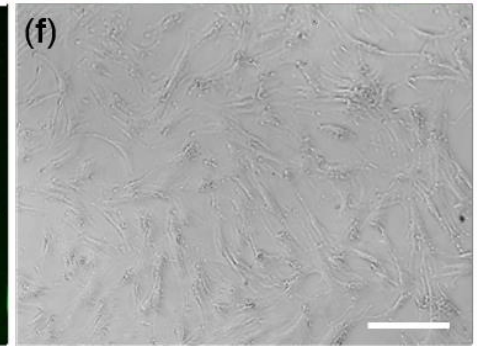

Figure 4. Immunofluorescent images of osteopontin following staining with anti-osteopontin antibody and the goat anti-mouse IgG-FITC stain (green) of hMSCs of: (a) control, (b) direct exposure with the air-flowing NTAPPJ for $4 \mathrm{~min}$, (c) media-treatment exposure with the air-flowing NTAPPJ for $4 \mathrm{~min}$, (d) direct exposure with the nitrogen-flowing NTAPPJ for $4 \mathrm{~min}$, and (e) media-treatment exposure with the nitrogen-flowing NTAPPJ for $4 \mathrm{~min}$. (f) Brightfield image of control. Scale bar is $100 \mu \mathrm{m}$.

Finally, the formation of mineralized tissues was examined by considering calcium deposition as indicated by the alizarin red staining (Figure 5). The results were similar to the trends reported in the other results: the hMSCs directly exposed to $4 \mathrm{~min}$ of the air-flowing NTAPPJ by the direct and media-treatment methods showed significantly higher levels of optical density $(p<0.05)$ as did the hMSCs exposed to 4 min of the nitrogen-flowing NTAPPJ by the direct method.

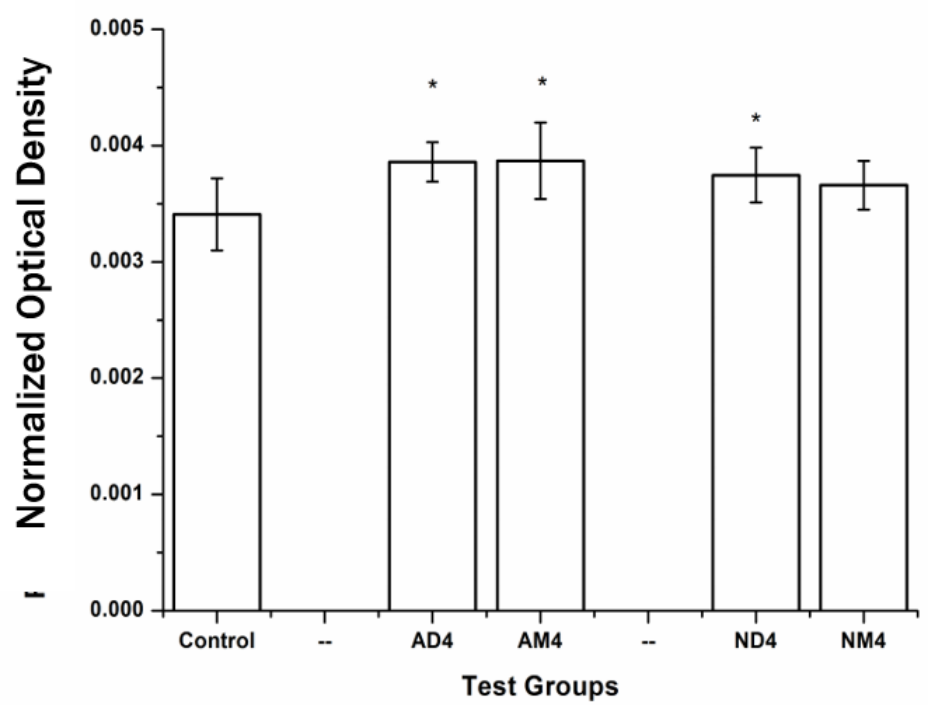

Figure 5. Optical density indicating the calcium deposition according to alizarin red staining and normalized by dividing the measured absorbance by the percentage of the cells attached (* significant at $p<0.05)$. 


\section{Discussion}

In this study, the effects of an NTAPPJ with varying levels of supply gas and exposure time on the differentiation of hMSCs were considered in terms of three possible differentiation states of hMSCs: adipogenesis, chondrogenesis, and osteogenesis.

The experiments were carried out while cells were suspended in medium, rather than fully attached and cultured, in order to accurately assess the attachment of the hMSCs [12,13]. However, despite the similar conditions, the same NTAPPJ treatments, and the previous results in which the mouse osteoblasts showed an increased number of cells attached after the NTAPPJ exposure [13], here the results with hMSCs indicated minimal effects of the NTAPPJ exposure. This finding may be due to differences in the animal cell lines used in the previous study and the human cells used in this study. Animal cell lines exhibit heteroploid chromosome patterns, whereas human cells are diploid in nature, and these two types of cells are known to react differently to surrounding chemicals [19].

Cell attachment is important in cellular activity as it may subsequently affect both the cell proliferation and differentiation [23]. The results for the numbers of cells attached following the NTAPPJ exposure (Figure 1) indicated that there were no significant differences in the numbers of cells attached, except for those cells exposed to 4 min of the NTAPPJ by the direct method, which showed a slight but significant increase in number (Figure 1a). The results concur with the results of experiments under similar conditions that considered exposures of no longer than $4 \mathrm{~min}[7,8,13]$. Additionally, the morphology of cells appeared similar between the NTAPPJ-exposed and control cells (Figure 2).

Previous studies investigated the effects of non-thermal plasma on the attachment and proliferation of cells [13-15]. In a previous study that applied helium-based NTAPPJ to adipose-tissue-derived stem cells, more cells proliferated with the NTAPPJ exposure and their stem-like properties were unaffected [16]. Here, different gas sources were used for the NTAPPJ and the focus was on markers of stemness-namely, CD44 and CD105. In another study in which the effect of the helium-gas-supplied NTAPPJ exposure was considered on human mesenchymal stem cells isolated from periodontal ligaments (hPDL-MSCs), it was evident that the hPDL-MSCs possessed all the typical MSC properties, including the capacity for multilineage differentiation [17]. Hence, this study is unique because, to the best of our knowledge, it is the first to investigate the effects of non-thermal atmospheric pressure plasma on the differentiation of human mesenchymal stem cells using air or nitrogen as the source with the results based on the genetic markers related to adipogenesis, chondrogenesis, and osteogenesis.

In the physiological state, the differentiation of stem cells is known to be affected by the interactions between cells and the extracellular matrix (ECM), which results in cell-signaling cascades [2]. Therefore, the extracellular environment in tissue engineering is important for the control of cell functions, where the biomimetic chemical functionalities surrounding the cells have been shown to affect the differentiation of stem cells [24].

The application of the NTAPPJ to the hMSCs by both the direct and media-treatment methods resulted in changes in the chemicals in the medium by the interactions between electrons, various ions, and radicals from the plasma with the proteins and ions in the medium. Such chemical changes may have resulted in chemical changes to the extracellular environment, as well as in cellular differentiation. This explains the increased differentiation of stem cells in both the directly treated and media-treated groups for chondrogenesis and osteogenesis (Figure 3b,c). In fact, it is already known that chemicals such as $\mathrm{OH}^{-}$or $\mathrm{COO}^{-}$result in increased chondrogenesis [25,26]. Additionally, oxygen-related chemicals were formed more actively when air was used as the source of the NTAPPJ, which may explain the general trend of more significantly increased differentiation in the cells exposed to the air-flowing NTAPPJ than was observed for the cells exposed to the nitrogen-flowing NTAPPJ. However, this does not explain why the hMSCs exposed to the NTAPPJ by the direct method showed a more significant increase in differentiation than the hMSCs exposed to the NTAPPJ by the media-treatment method in adipogenesis (Figure 3a).

It is well known that plasma produces both long-lived and short-lived reactive oxygen species (ROS) [14], and the dose of such species may also affect cellular functions. On the other hand, it has 
already been well established that ROS are linked to the activity of stem cells, such as in bone marrow monocyte-macrophage lineage cells or hematopoietic stem cells $[27,28]$. Additionally, it was previously reported that such ROS may act as secondary messengers in intracellular signal transduction and therefore result in increased adipogenesis [29-31]. Hence, the result of adipogenesis by hMSCs may have been affected by the ROS, which were short lived in the media and therefore had less effect on hMSCs exposed to the NTAPPJ by the media-treatment method.

Successful hard tissue regeneration often relies on the formation of either cartilage or bone tissue while avoiding the formation of adipose tissue $[3,24]$. Hence, directing the differentiation of the hMSCs through either chondrogenesis or osteogenesis and avoiding adipogenesis would be useful in such a scenario. Further in vivo or in vitro experiments are warranted to confirm the formation of the relevant proteins associated with each of these differentiation pathways. Despite the limitations of this study, the use of the media-treatment method for exposure by an NTAPPJ is expected to be a useful method for selectively guiding hMSC differentiation into hard-tissue-related cells while suppressing adipogenic differentiation, although further investigation is needed to confirm the likelihood of this outcome.

\section{Conclusions}

In this study, the effects of a non-thermal atmospheric pressure plasma jet with an air or nitrogen source on the differentiation of human mesenchymal stem cells were investigated. The results showed that different conditions of plasma exposure resulted in different levels of cellular differentiation. These results may be linked to both the chemicals of the extracellular environment and the reactive oxygen species produced by the plasma, and further investigations will also be helpful to correctly drive the differentiation of the stem cells into the desired tissue.

Nevertheless, it was shown that the non-thermal atmospheric pressure plasma jet with air or nitrogen is a useful tool in the differentiation of human mesenchymal stem cells and has possible applications in tissue engineering.

Author Contributions: Conceptualization, J.-S.K., N.K., E.H.C., and K.-M.K.; methodology, J.-S.K., T.-Y.K., and E.H.C.; formal analysis, J.-S.K.; investigation, J.-S.K. and T.-Y.K.; writing-original draft preparation, J.-S.K., N.K., E.H.C., and K.-M.K.; writing-revised draft preparation, T.-Y.K.; funding acquisition, J.-S.K., and E.H.C.

Funding: This work was supported by the Technology Innovation Program (or Industrial Strategic Technology Development Program) 20002402, Development of international standardization for atmospheric pressure low temperature plasma medical devices for healing wounds and dental disease) funded by the Ministry of Trade, Industry \& Energy (MOTIE, Korea) and this study was supported by the Yonsei University College of Dentistry (6-2019-0021).

Acknowledgments: The plasma source was kindly provided by the Plasma Bioscience Research Center, Kwangwoon University.

Conflicts of Interest: The authors declare no conflicts of interest.

\section{References}

1. Mason, C.; Dunnill, P. A brief definition of regenerative medicine. Regen. Med. 2008, 3. [CrossRef] [PubMed]

2. Bianco, P.; Riminucci, M.; Gronthos, S.; Robey, P.G. Bone marrow stromal stem cells: Nature, biology, and potential applications. Stem Cells 2001, 19, 180-192. [CrossRef] [PubMed]

3. Barry, F.; Boynton, R.E.; Liu, B.S.; Murphy, J.M. Chondrogenic differentiation of mesenchymal stem cells from bone marrow: Differentiation-dependent gene expression of matrix components. Exp. Cell Res. 2001, 268, 189-200. [CrossRef] [PubMed]

4. Jaiswal, N.; Haynesworth, S.E.; Caplan, A.I.; Bruder, S.P. Osteogenic differentiation of purified, culture-expanded human mesenchymal stem cells in vitro. J. Cell Biochem. 1997, 64, 295-312. [CrossRef]

5. Matsushita, K.; Wu, Y.; Okamoto, Y.; Pratt, R.E.; Dzau, V.J. Local renin angiotensin expression regulates human mesenchymal stem cell differentiation to adipocytes. Hypertension 2006, 48, 1095-1102. [CrossRef] [PubMed]

6. Toma, C.; Pittenger, M.F.; Cahill, K.S.; Byrne, B.J.; Kessler, P.D. Human mesenchymal stem cells differentiate to a cardiomyocyte phenotype in the adult murine heart. Circulation 2002, 105, 93-98. [CrossRef] [PubMed] 
7. Kwon, J.S.; Kim, Y.H.; Choi, E.H.; Kim, K.N. Development of ultra-hydrophilic and non-cytotoxic dental vinyl polysiloxane impression materials using a non-thermal atmospheric-pressure plasma jet. J. Phys. D Appl. Phys. 2013, 46, 195201. [CrossRef]

8. Lee, E.J.; Kwon, J.S.; Uhm, S.H.; Song, D.H.; Kim, Y.H.; Choi, E.H.; Kim, K.N. The effects of non-thermal atmospheric pressure plasma jet on cellular activity at SLA-treated titanium surfaces. Curr. Appl. Phys. 2013, 13, S36-S41. [CrossRef]

9. Laroussi, M.; Tendero, C.; Lu, X.; Alla, S.; Hynes, W.L. Inactivation of bacteria by the plasma pencil. Plasma Process Polym. 2006, 3, 470-473. [CrossRef]

10. Sladek, R.E.J.; Stoffels, E. Deactivation of Escherichia coli by the plasma needle. J. Phys. D Appl. Phys. 2005, 38, 1716-1721. [CrossRef]

11. Fridman, G.; Peddinghaus, M.; Ayan, H.; Fridman, A.; Balasubramanian, M.; Gutsol, A.; Brooks, A.; Friedman, G. Blood coagulation and living tissue sterilization by floating-electrode dielectric barrier discharge in air. Plasma Chem. Plasma Process. 2006, 26, 425-442. [CrossRef]

12. Kieft, I.E.; Kurdi, M.; Stoffels, E. Reattachment and apoptosis after plasma-needle treatment of cultured cells. IEEE Trans. Plasma Sci. 2006, 34, 1331-1336. [CrossRef]

13. Kwon, J.S.; Kim, Y.H.; Choi, E.H.; Kim, K.N. The effects of non-thermal atmospheric pressure plasma jet on attachment of osteoblast. Curr. Appl. Phys. 2013, 13, S42-S47. [CrossRef]

14. Kalghatgi, S.; Kelly, C.M.; Cerchar, E.; Torabi, B.; Alekseev, O.; Fridman, A.; Friedman, G.; Azizkhan-Clifford, J. Effects of Non-Thermal Plasma on Mammalian Cells. PLoS ONE 2011, 6, e16270. [CrossRef] [PubMed]

15. Kalghatgi, S.; Friedman, G.; Fridman, A.; Clyne, A.M. Endothelial Cell Proliferation is Enhanced by Low Dose Non-Thermal Plasma Through Fibroblast Growth Factor-2 Release. Ann. Biomed. Eng. 2010, 38, 748-757. [CrossRef] [PubMed]

16. Park, J.; Lee, H.; Lee, H.J.; Kim, G.C.; Kim, D.Y.; Han, S.; Song, K. Non-Thermal Atmospheric Pressure Plasma Efficiently Promotes the Proliferation of Adipose Tissue-Derived Stem Cells by Activating NO-Response Pathways. Sci. Rep. 2016, 6, 39298. [CrossRef] [PubMed]

17. Miletic, M.; Mojsilovic, S.; Dordevic, I.O.; Maletic, D.; Puac, N.; Lazovic, S.; Malovic, G.; Milenkovic, P.; Petrovic, Z.L.; Bugarski, D. Effects of non-thermal atmospheric plasma on human periodontal ligament mesenchymal stem cells. J. Phys. D Appl. Phys. 2013, 46, 345401. [CrossRef]

18. Lazovic, S.; Puac, N.; Miletic, M.; Pavlica, D.; Jovanovic, M.; Bugarski, D.; Mojsilovic, S.; Maletic, D.; Malovic, G.; Milenkovic, P.; et al. The effect of a plasma needle on bacteria in planktonic samples and on peripheral blood mesenchymal stem cells. New J. Phys. 2010, 12, 083037. [CrossRef]

19. Kwon, J.S.; Illeperuma, R.P.; Kim, J.; Kim, K.M.; Kim, K.N. Cytotoxicity evaluation of zinc oxide-eugenol and non-eugenol cements using different fibroblast cell lines. Acta Odontol. Scand. 2014, 72, 64-70. [CrossRef] [PubMed]

20. Kwon, J.S.; Lee, S.B.; Kim, C.K.; Kim, K.N. Modified cytotoxicity evaluation of elastomeric impression materials while polymerizing with reduced exposure time. Acta Odontol. Scand. 2011, 70, 597-602. [CrossRef] [PubMed]

21. Denhardt, D.T.; Guo, X.J. Osteopontin-A Protein with Diverse Functions. FASEB J. 1993, 7, $1475-1482$. [CrossRef] [PubMed]

22. Rosen, E.D.; Walkey, C.J.; Puigserver, P.; Spiegelman, B.M. Transcriptional regulation of adipogenesis. Gene Dev. 2000, 14, 1293-1307. [PubMed]

23. Lai, H.C.; Zhuang, L.F.; Liu, X.; Wieland, M.; Zhang, Z.Y.; Zhang, Z.Y. The influence of surface energy on early adherent events of osteoblast on titanium substrates. J. Biomed. Mater. Res. A 2010, 93, 289-296. [CrossRef] [PubMed]

24. Benoit, D.S.W.; Schwartz, M.P.; Durney, A.R.; Anseth, K.S. Small functional groups for controlled differentiation of hydrogel-encapsulated human mesenchymal stem cells. Nat. Mater. 2008, 7, 816-823. [CrossRef] [PubMed]

25. Guo, L.; Kawazoe, N.; Fan, Y.; Ito, Y.; Tanaka, J.; Tateishi, T.; Zhang, X.; Chen, G. Chondrogenic differentiation of human mesenchymal stem cells on photoreactive polymer-modified surfaces. Biomaterials 2008, 29, $23-32$. [CrossRef] [PubMed]

26. Phillips, J.E.; Petrie, T.A.; Creighton, F.P.; Garcia, A.J. Human mesenchymal stem cell differentiation on self-assembled monolayers presenting different surface chemistries. Acta Biomater. 2010, 6, 12-20. [CrossRef] [PubMed] 
27. Ito, K.; Hirao, A.; Arai, F.; Takubo, K.; Matsuoka, S.; Miyamoto, K.; Ohmura, M.; Naka, K.; Hosokawa, K.; Ikeda, Y.; et al. Reactive oxygen species act through p38 MAPK to limit the lifespan of hematopoietic stem cells. Nat. Med. 2006, 12, 446-451. [CrossRef] [PubMed]

28. Lee, N.K.; Choi, Y.G.; Baik, J.Y.; Han, S.Y.; Jeong, D.W.; Bae, Y.S.; Kim, N.; Lee, S.Y. A crucial role for reactive oxygen species in RANKL-induced osteoclast differentiation. Blood 2005, 106, 852-859. [CrossRef] [PubMed]

29. Lee, H.; Lee, Y.J.; Choi, H.; Ko, E.H.; Kim, J.W. Reactive Oxygen Species Facilitate Adipocyte Differentiation by Accelerating Mitotic Clonal Expansion. J. Biol. Chem. 2009, 284, 10601-10609. [CrossRef] [PubMed]

30. Sauer, H.; Rahimi, C.; Hescheler, J.; Wartenberg, M. Role of reactive oxygen species and phosphatidylinositol 3-kinase in cardiomyocyte differentiation of embryonic stem cells. FEBS Lett. 2000, 476, 218-223. [CrossRef]

31. Sundaresan, M.; Yu, Z.X.; Ferrans, V.J.; Irani, K.; Finkel, T. Requirement for Generation of H2o2 for Platelet-Derived Growth-Factor Signal-Transduction. Science 1995, 270, 296-299. [CrossRef] [PubMed]

(C) 2019 by the authors. Licensee MDPI, Basel, Switzerland. This article is an open access article distributed under the terms and conditions of the Creative Commons Attribution (CC BY) license (http://creativecommons.org/licenses/by/4.0/). 